\title{
Health promoting hospitals in Iran: A review of the current status, challenges, and future prospects
}

\author{
Yadollah Hamidi ${ }^{1}$, Seyed Mohammad Mahdi Hazavehei ${ }^{2}$, Akram Karimi-Shahanjarini ${ }^{3}$, \\ Mohamad Ali Seif Rabiei ${ }^{4}$, Maryam Farhadian ${ }^{5}$, Shohreh Alimohamadi ${ }^{6}$, Seyedeh Melika Kharghani Moghadam*2
}

\section{Abstract}

Background: Health promoting hospitals (HPHs), in addition to their routine diagnosis and treatment services, concentrate on health enhancement and disease prevention. This study was conducted to systematically review studies conducted in the field of health promoting hospitals (HPH) in Iran to achieve HPH standards.

Methods: Electronic search was conducted from October to February 2016 in Persian and English databases. Search was done IranMedex, SID, ISI Web of Knowledge, ScienceDirect, PubMed, and Google Scholar with the following keywords: Health promotion hospital (s), health promoting hospital (s), health promotion hospitals, HPH, and Iran. Based on inclusion and exclusion criteria and the aim of the study, 10 studies were selected to be reviewed.

Results: The results showed that HPH standards in studied hospitals were very poor in overall standard and that the standard of management policy had the lowest mean. Studies conducted in the order modeling HPH in Iran showed that factors of patient empowerment and society had the greatest impact and needs assessment had the lowest impact. The results of interventional studies were reviewed in this study and it was found that implementing standards of HPH and educational interventions increase the standard of $\mathrm{HPH}$.

Conclusion: The review of the HPH studied indicated that the most important challenge in achieving the standards of health promotion hospitals is Iran's hospital policy, which is more treatment-oriented.

Keywords: Health Promotion, Health Promoting Hospital, Iran Hospitals, HPH

Conflicts of Interest: None declared

Funding: Hamadan University of Medical Sciences

*This work has been published under CC BY-NC-SA 1.0 license.

Copyright $($ Iran University of Medical Sciences

Cite this article as: Hamidi Y, Hazavehei SMM, Karimi-ShahanjariniA, Seif Rabiei MA, Farhadian M, Alimohamadi Sh, Kharghani Moghadam SM. Health promoting hospitals in Iran: A review of the current status, challenges, and future prospects. Med J Islam Repub Iran. 2019 (27 May);33:47. https://doi.org/10.47176/mjiri.33.47

\section{Introduction}

Global changes have caused new challenges in health, especially in hospitals (1), because hospitals can have lasting effects on the behavior of patients and their families (2). In the early 1990s, the World Health Organization (WHO), in an international initiative, launched an international network of health promoting hospitals (HPH) to

Corresponding author: Seyedeh Melika Kharghani Moghadam,m_kharghani@yahoo.com

1. Department of Health Management and Economics, School of Public Health and Research Center for Health Sciences, Hamadan University of Medical Sciences, Hamadan, Iran

2. Department of Public Health, School of Public Health, Hamadan University of Medical Sciences, Hamadan, Iran

3. Social Determinants of Health Research Center, Department of Public Health, School of Public Health, Hamadan University of Medical Sciences, Hamadan, Iran

4. Community Medicine Department, School of Medicine, Hamadan University of Medical Sciences, Hamadan, Iran

5. Department of Biostatistics, School of Public Health and Research Center for Health Sciences, Hamadan University of Medical Sciences, Hamadan, Iran

6. Faculty of Medicine, Hamadan University of Medical Sciences, Hamadan, Iran support hospitals in health promotion. The goal of hospitals that joined the international network of HPH was to provide comprehensive and high-quality medical and nursing services using health promotion activities for patients, employees, and society in their legal identity and their daily activities (3). HPH have committed to imple-

$\uparrow$ What is "already known" in this topic:

Health promoting hospitals (HPHs), in addition to their routine diagnosis and treatment services, concentrate more on health enhancement and disease prevention. HPH standards in Iran's hospitals are weak.

\section{$\rightarrow$ What this article adds:}

The most important challenge in achieving the standards of HPH is Iran's hospital policy, which is more treatmentoriented. Thus, to transform the hospital system to HPH in Iran, the treatment-oriented policy of hospitals should be changed to a health-promoting policy. 
ment health promotion in daily activities and to follow recommendations of institutions to promote health (1). The standards of HPH have focused on creating hospital systems to form an efficient organization (4) whose strategies act in coordination with one another (5). Hospitals affect public health in 2 ways: (1) prevention, treatment, and rehabilitation; (2) impacting the society and its surroundings. Moreover, hospitals can promote health in the society by contributing to the entire cycle of health, including public health education and disease prevention, proper care in case of chronic diseases, timely diagnosis, and accurate treatment of diseases and ultimately help the patients to return to their normal life after an illness through rehabilitation (2). In fact, the function of hospital is beyond providing specialized and clinical services. In fact, planning to provide health services and promote health of the society are the key functions of this institution. In addition to providing common diagnostic and treatment services, the emphasis of HPH is more on health promotion and disease prevention. The mission of $\mathrm{HPH}$ is change of treatment-oriented attitude to health-oriented attitude $(6,7)$. Benefits of HPH include reduced rehospitalization of patients, improving the quality of life of patients, and reducing the cost of therapy $(8,9)$. However, most of Iranian hospitals are treatment-oriented and patient-oriented and have no active role in disease prevention and promotion of healthy lifestyle and behavior (10). In Iran, about $70 \%$ of the health budget is allocated to hospitals (11). The problem of shortage of resources is another issue raised in the health sector, particularly in hospitals. One of the most important resources is hospital beds. According to the above statistics, health system must adopt strategies to reduce the rate of hospitalization. Hospitals should move towards health promoting services; and changing the role of the hospitals from treatment to prevention is one of these strategies. In addition, researches in Iran have revealed that the maximum number of manpower with specialized degrees is employed in the health sector and the most expensive and the most com- plex equipment is used in hospitals (12). If hospitals move towards providing prevention services, promoting health, and reducing the percentage of costs spent on treatment, the health sector can save millions in budget allocation. Hospitals have a great relationship with the society and they have the potential to influence public policies in other sectors. Therefore, it seems that the establishment of HPH can improve the health of patients, employees, and the society. Also, transforming hospitals into health promoting organizations and changing their purely treatment functions to prevention services and improving service quality will lead to reduced costs, improved performance, expanded hospital services, and improved communication with patients. Also, when providing health services, hospitals will pay attention to social, political, economic, and cultural conditions. Such hospitals should be able to use health resources in the society to promote health and reduce health gaps in the society. Implementing educational interventions based on moving towards HPH may highlight the role of social responsibility in hospitals because hospitals, as a material and social environment, both affect the health of individuals within their premises and affect the life and health of people living in the vicinity. Therefore, the present study was conducted to review the current status, challenges, and future prospects of HPH in Iran.

\section{Methods}

\section{Paper search procedure}

This study was conducted to systematically review the studies conducted on HPH in Iran to meet HPH standards. Electronic search was conducted from October to February 2016 in Persian and English databases. Search was conducted in d IranMedex, SID, ISI Web of Knowledge, ScienceDirect, PubMed, and Google Scholar with the following keywords: health promotion hospital (s), health promoting hospital (s), health promotion hospitals, Iran.

To select the studies, inclusion and exclusion criteria were defined.

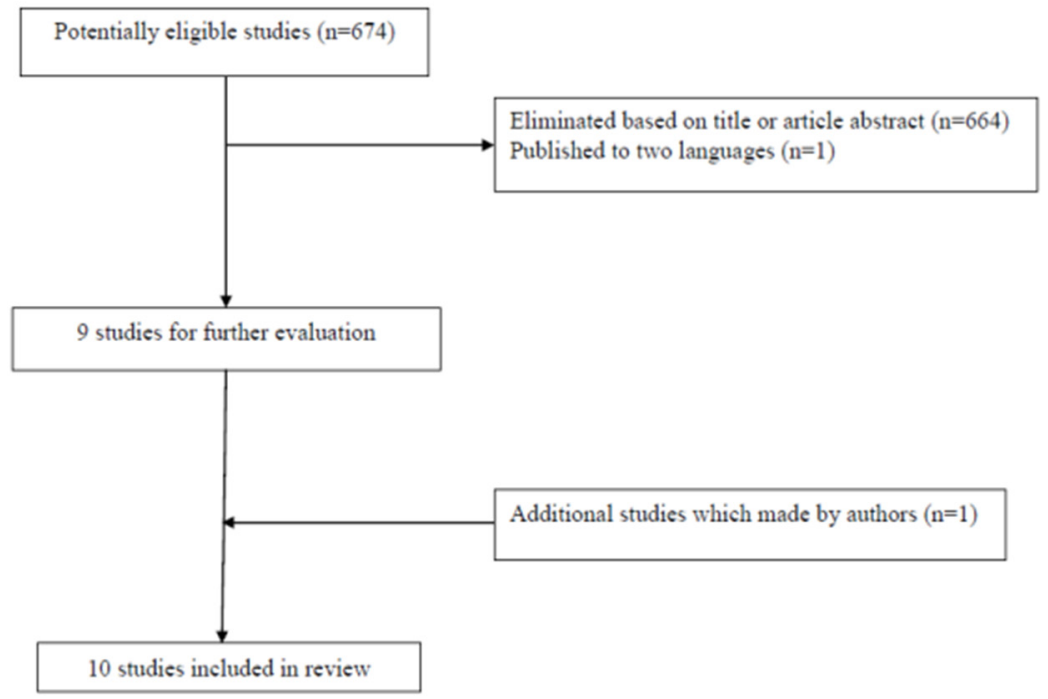

Fig. 1. The process of articles selection 
Inclusion criteria: any study (descriptive, intervention, qualitative) conducted with HPH approach. Exclusion criteria included studies that have not been conducted in Iran's hospitals or studies that used systematic and metaanalysis approaches. Figure 1 displays the selection process of proper studies in this review study based on electronic resources search.

\section{Data extraction}

The research team searched the papers based on keywords on any search database and entered all the papers into EndNote 6 software to determine their quality and selection of the studies that met the inclusion criteria. The research team excluded the papers that had no adequate quality based on the research objective.

Information of each study was extracted independently by 2 researchers and recorded in a standard form developed by the researchers. The extracted data included information about the studied hospitals, target group studied, study design, study methods, and results and qualitative aspects. The difference related to the extraction of information was solved using a consensus. This part of the work was done from March to June 2016.

\section{Selection of studies}

In total, 674 studies published in Persian and English languages were obtained in the initial search. After examining the titles and abstracts of papers and considering the inclusion and exclusion criteria, 665 papers that were not in line with the objectives of the study were excluded. Information of a study conducted by the author was also used in this review study (Fig. 1). Finally, 10 studies were selected to be examined and analyzed. Among the studies reviewed, 2 were descriptive and were conducted to evaluate the status of HPH using the HPH questionnaire of the WHO $(13,14), 4$ were descriptive and were conducted to offer HPH model (15-18), 2 were interventional with the aim of implementing HPH programs $(19,20)$, and 1 was qualitative (21). In addition, the results were obtained from the thesis conducted by the corresponding author, which was performed on a specialized hospital in Hamadan University of Medical Sciences (22). The selected studies were analyzed separately for type of study.

\section{Results}

\section{Studies based on HPH standards}

Table 1 demonstrates the results of the studies conducted on the standards of the WHO HPH in various cities of Iran. Management policy standard, continuity and cooperation, and promoting a healthy workplace had the weakest values among the standards (Table 1). In general, studied hospitals were not in a good condition in terms of HPH standards. Another interesting point was the difference in standard values in private and public hospitals; in most cases (apart from WHO standards of HPH), private hospitals had a better condition in patient assessment. According to current statistics, 570 public hospitals and 337 private hospitals are active in the country (23).

Figure 2 demonstrates the results of the studies performed by examining HPH standards. This figure clearly shows that all hospitals are very poor in the overall standard and that the standard of management policy had the lowest mean.

\section{Studies based on proposal and design of HPHs model}

Figure 3 shows studies based on the proposal and design of HPH model, factors affecting the hospital, and level of impact of each factor. As Figure 2 displays, in the first study model, 5 factors are involved in HPH, among which patient empowerment and needs assessment had the greatest and the lowest impact, respectively. In the second study model, 6 factors were involved in $\mathrm{HPH}$, among which society and management had the greatest and lowest impact, respectively.

In their study, Yaghubi et al developed a conceptual model to identify factors affecting the implementation of HPH (17). This model was designed with adaptive method and model information was collected in the form of library studies. The developed model showed that related factors included society, management, policy-making, techniques for project implementation, development and dissemination, and evaluation of factors affecting the implementation of HPH (17).

Yaghubi et al conducted a study entitled, "Factors Affecting the Implementation of the HPH in Selected Hospitals of Isfahan", to determine the factors involved in HPH in 2013. Results showed that among the effective components, needs assessment of health promotion for patient groups, employees' empowerment to promote health, de-

Table 1. The health promoting hospital studies based on HPH standards

\begin{tabular}{|c|c|c|c|c|c|c|c|c|c|}
\hline City of study & 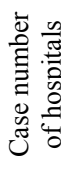 & 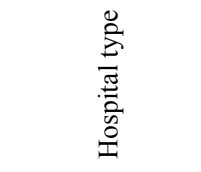 & 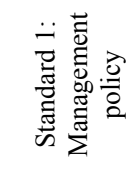 & 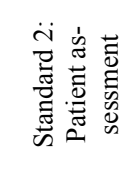 & 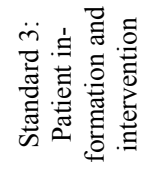 & 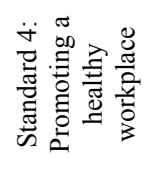 & 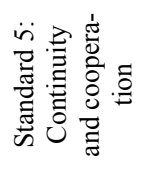 & 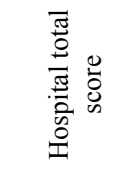 & 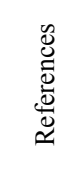 \\
\hline $\begin{array}{l}\text { Tehran } \\
\text { Esfahan }\end{array}$ & 38 & $\begin{array}{c}\text { Government } \\
\text { Hospital }\end{array}$ & $53.5 \pm 16.6$ & $44.4 \pm 24.6$ & $69 \pm 9.4$ & $53.4 \pm 16.4$ & $38.8 \pm 8.9$ & $51.3 \pm 14.1$ & (13) \\
\hline Shiraz & & Private Hospital & $54.4 \pm 9.7$ & $43.5 \pm 5.1$ & $75 \pm 8.6$ & $60.1 \pm 13.6$ & $57.8 \pm 13.4$ & $56.9 \pm 16.1$ & \\
\hline Gilan & & Total & $53.8 \pm 14.2$ & $44.2 \pm 20.1$ & $70.8 \pm 8.1$ & $55.5 \pm 14.1$ & $44.7 \pm 11.1$ & $54.1 \pm 15.1$ & \\
\hline Isfahan & 9 & $\begin{array}{c}\text { Government } \\
\text { Hospital }\end{array}$ & $39.2 \pm 11.4$ & $52.8 \pm 16.2$ & $79.8 \pm 13.5$ & $56.2 \pm 12.5$ & $36.2 \pm 10.8$ & $48.8 \pm 9.8$ & (14) \\
\hline Hamadan & 2 & $\begin{array}{c}\text { Government } \\
\text { Hospital }\end{array}$ & $35.5 \pm 8.7$ & $53.1 \pm 13.2$ & $62.5 \pm 2.3$ & $31.2 \pm 13.2$ & $65.8 \pm 3.7$ & $48.2 \pm 7.8$ & $(22)$ \\
\hline
\end{tabular}




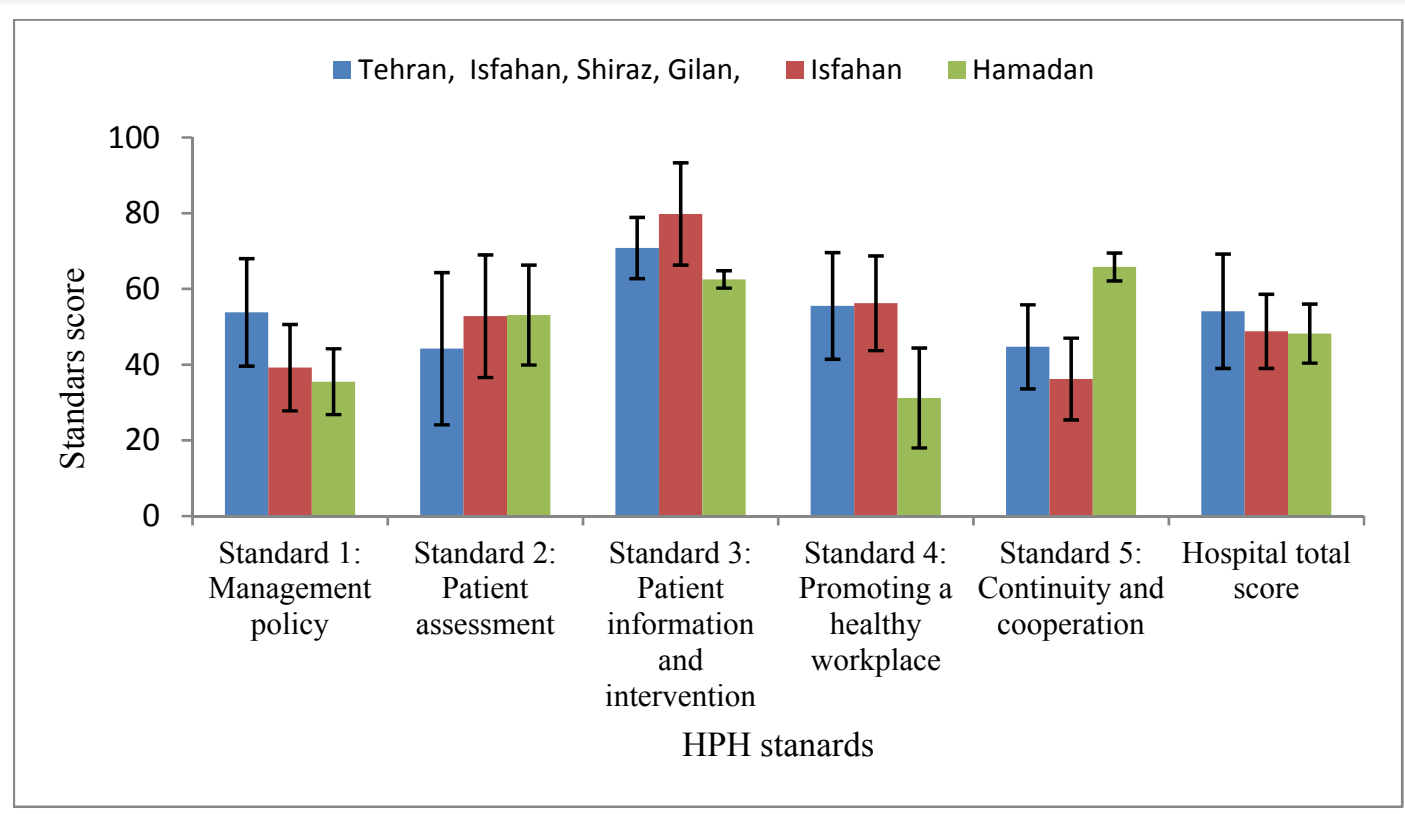

Fig. 2. HPH standards in investigated studies

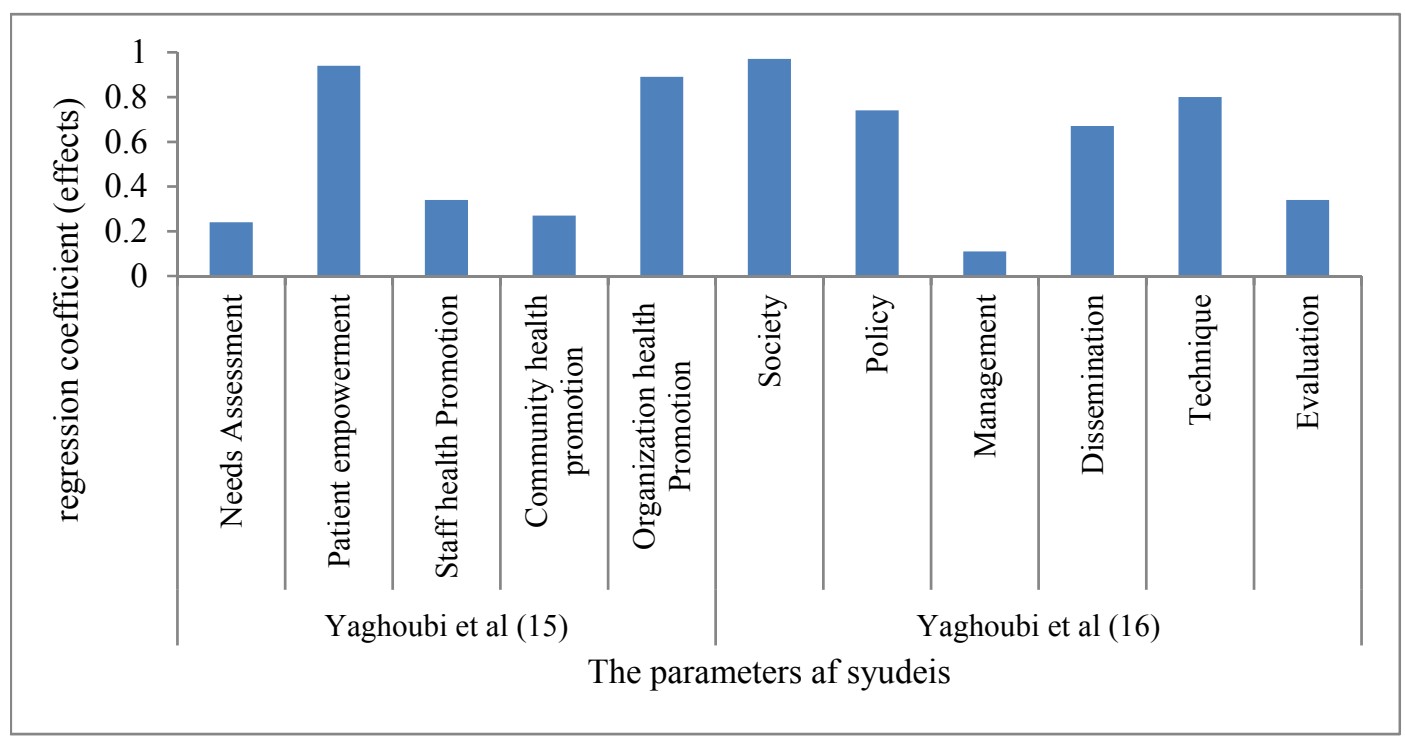

Fig. 3. HPHs Models in Iran

fining safety and health requirements in workplace, and empowerment of the society to manage diseases had the highest impact (18).

\section{Intervention-based studies in line with $\mathrm{HPH}$}

Table 2 displays the results of the intervention of establishment of HPH standards in increasing values of $\mathrm{HPH}$ standards. In a study conducted in the city of Sharoud, 2 hospitals similar in infrastructure were selected. In one of the hospitals, HPH standards were implemented as an intervention (case hospital), but in the control hospital no intervention was implemented. Table 2 demonstrates that the standard values of HPH increased as a result of interventions and that the greatest role of interventions was seen in standard 4 (promoting a healthy workplace) and standard 1 (management policy).

Table 3 demonstrates the results of an intervention study with HPH approach in Qazvin, taking 4 dimensions into account: (1) patient empowerment, (2) educational nurses, (3) organizational management, and (4) physical environment for intervention. Different models of health education intervention models were used for each dimension and the greatest impact of interventions was seen in the patient attitude dimension (Table 3 ).

\section{Qualitative studies}

Keshavarz et al conducted a qualitative study entitled, "Explaining the Viewpoints of Health Employees on Hospital Effect on Them: HPH Approach" in 5 hospitals through half-structured interviews with 45 medical staff in 2012. The aim of this study was to evaluate the viewpoints and experiences of the hospital personnel on the effect of hospital effect on their health; the positive results were increased awareness and knowledge and easy access to medical facilities and the negative results were psychological and physical effects, fatigue, and disease. Interviewees' 
Y. Hamidi, et al.

\begin{tabular}{|c|c|c|c|c|c|c|c|c|}
\hline Hospital type & $\begin{array}{l}\text { Standard 1: } \\
\text { Management } \\
\text { policy } \\
\end{array}$ & $\begin{array}{l}\text { Standard 2: } \\
\text { Patient } \\
\text { assessment }\end{array}$ & $\begin{array}{l}\text { Standard 3: Patient } \\
\text { information and } \\
\text { intervention }\end{array}$ & $\begin{array}{c}\text { Standard 4: } \\
\text { Promoting a } \\
\text { healthy workplace }\end{array}$ & \multicolumn{2}{|c|}{$\begin{array}{l}\text { Standard 5: } \\
\text { Continuity and } \\
\text { cooperation }\end{array}$} & $\begin{array}{l}\text { Hospital } \\
\text { total score }\end{array}$ & References \\
\hline $\begin{array}{l}\text { Case } \\
\text { Hospital }\end{array}$ & $14.6 \pm 1.3$ & $13.4 \pm 0.9$ & $11.8 \pm 0.5$ & $17.6 \pm 1.6$ & 14.8 & & $72.3 \pm 4.1$ & (19) \\
\hline Control Hospital & $3.0 \pm 1.5$ & $5.3 \pm 2.7$ & $4.1 \pm 2.1$ & $2.6 \pm 2.4$ & 1.3 & & $16.3 \pm 7.5$ & \\
\hline Patient empowerment & Health be & model & $\begin{array}{c}\text { Knowledge } \\
\text { Attitude }\end{array}$ & $\begin{array}{l}\text { Before } \\
\text { After } \\
\text { Before } \\
\text { After }\end{array}$ & $\begin{array}{c}9.4 \\
14.1 \\
140.7 \\
165.2\end{array}$ & $\begin{array}{c}4.5 \\
6.4 \\
74.5 \\
36.7\end{array}$ & 0.02 & $(20)$ \\
\hline $\begin{array}{l}\text { Educational } \\
\text { intervention for nurses }\end{array}$ & BAS & & Communication skills & $\begin{array}{l}\text { Before } \\
\text { After }\end{array}$ & $\begin{array}{l}11.3 \\
17.0\end{array}$ & $\begin{array}{l}4.1 \\
2.7\end{array}$ & $<0.05$ & \\
\hline $\begin{array}{l}\text { Organizational } \\
\text { intervention for } \\
\text { management }\end{array}$ & $\begin{array}{r}\text { Total } \\
\text { managem }\end{array}$ & $\begin{array}{l}\text { lity } \\
\text { (TQM) }\end{array}$ & Total Quality Management & $\begin{array}{l}\text { Before } \\
\text { After }\end{array}$ & $\begin{array}{l}261.4 \\
263.4\end{array}$ & $\begin{array}{l}51.1 \\
51.2\end{array}$ & 0.15 & \\
\hline $\begin{array}{l}\text { Physical environment } \\
\text { intervention }\end{array}$ & Chec & & $\begin{array}{c}\text { Kitchen } \\
\text { Laundry room }\end{array}$ & $\begin{array}{l}\text { Before } \\
\text { After } \\
\text { Before } \\
\text { After }\end{array}$ & $\begin{array}{c}190 \\
207 \\
60 \\
66\end{array}$ & $\begin{array}{l}- \\
- \\
- \\
-\end{array}$ & - & \\
\hline
\end{tabular}

suggestions for creating a healthier workplace included improving communication, management, welfare facilities and human resources, and creating a mentally healthy environment, infection control, holding educational classes, and paying more attention to patients (21).

\section{Discussion}

The results of this study showed that HPH standards in studied hospitals was weak. Moreover, the studied hospitals are hospitals of the most important and major cities of Iran, making this problem even more alarming. HPH standards in hospitals of deprived cities is even worse. Until the late 19th century, hospitals were both a place for providing health care and a place to lose life. This was changed with the development of medical science and expansion of humanitarian and utilitarian philosophy. Since then, the capacity of medical care increased to improve health and promote it by refining the methods of antiseptic, anesthesia, surgical skills and knowledge, trauma techniques, blood transfusion, coronary artery bypass, medicinal treatments, transplant, and minimally invasive surgery (24). There are several views on the impact of hospital health services on human. According to this network, hospital services should pay more attention to people's needs, meaning that in addition to the physiological parameters, they should pay attention to long-term health. The philosophy of promoting health hospitals is based on well-founded evidence and procedures that consider health promotion as the core of the hospital, as the quality strategies used in clinical settings to manage health organizations can also be used in the case of health promotion (8). Therefore, hospital organization and the impact of health services on health promotion gained importance. To support providing health promotion programs in hospitals, the World Health Organization's European Regional Office began the first international consultancy in 1988. In the next year, the World Health Organization's model project called "Health and Hospital" began to be implemented in Rudolfstiftung hospital in
Vienna, Austria, as a partner institution. Then, the movement of HPH entered the development phase, in which the experimental hospital project of World Health Organization's European Regional Office began to be implemented in 1993. This phase that lasted 4 years (1993-1997) included accurate monitoring of projects in 20 hospitals in 11 European countries. Following the completion of the experimental phase, national and regional networks were created and networking entered the consolidation phase. Since then, national and regional networks have been playing an important role in strengthening cooperation and exchange of experiences among hospitals of a region or country. In May 2005, an international network of HPH included 25 countries, 35 national and regional networks, and more than 700 hospitals $(8,25)$. In the past, projects implemented in the network of HPH were characterized by their traditional focus on health education interventions to patients and health of employees to some extent. At this time, the focus of HPH has been expanded and it now deals with social and organizational issues, such as changing the organizational culture and environmental issues. The future challenge of HPH is to integrate the organizational activities promoting health through continuous quality improvement, making clear similarities applied, focusing on the continuous development process, and applying, monitoring, assessing, and incorporating the principle of health promotion with organizational structure and culture (8).

The results of this study showed that among the studied standards, the standard of management policy in most cases had the weakest and lowest value. Focusing on hospital management is the third dimension of HPH approach. It seems that to achieve health promotion as the core of life quality, implementing the following concepts is essential: organizational requirements and commitment, actions based on evidence and information, management, committed and responsible management, and interaction and participation through approaches that govern the management $(20,26,27)$. Unfortunately, the policy of Minis- 
try of Health is more treatment-oriented and hospitals' management in line with the policy of the Ministry of Health focuses mainly on treatment and equipping hospital wards $(1,10)$. Although the mission and vision of hospitals is health promotion, due to the treatment-oriented policy of the Ministry of Health, the largest amount of budget and facilities of hospitals is allocated to treatment. To achieve the goals of health promotion in hospitals, this issue should be emphasized highly in Ministry of Health policies. The existence of the traditional view of treatment-oriented policy in health services network in Iran has caused hospitals to focus on the disease and treatment, and thus standards related to patient treatment are higher compared to other standards. However, life style or quality of life of patients after leaving the hospital is not considered. In general, the results showed that one of the most important challenges for hospitals of Iran is to achieve HPH standards. Therefore, to connect the country's hospitals to HPH network, the treatment-oriented policy of hospitals should be changed to a health promoting policy.

Studies conducted to model HPH in Iran showed that factors related to the society, needs assessment, patient empowerment, employees' health promotion, policymaking, management, project implementation techniques, development, and dissemination and assessment of the factors affect HPH implementation (15-18). All axes of health promotion of these studies are based on the axes suggested by the WHO standard; therefore, 5-part standards of the WHO were developed. All 4 axes mentioned in the study by Groene were mentioned in the models studied in these researches (15). In developed models of the reviewed studies, the factors of patient empowerment, society, and organization had the greatest impact on HPH. People empowerment to obtain a fuller potential for health is the basic principle of the Declaration of Ottawa (7). Generally, the focus of Declaration of Vienna is on providing people-oriented services for patients and their relatives to facilitate the process of improvement and contribution in empowering patients and creating close relationships with the society and other levels of the health care system (15). This declaration emphasizes the development of new strategies for implementation.

Interventional studies reviewed in this study were of 2 types: (1) interventions for implementing standards of $\mathrm{HPH}$ and (2) interventions using different educational models. The results showed an increase in the standard of $\mathrm{HPH}$. Comparing the results of this study with those of other studies $(28,29)$, indicated that the increase in the rate of standards in this study was relatively higher than that of other studies. According to the results of this study, this type of intervention can be implemented in all hospitals of Iran to achieve HPH standards and connect Iran's hospitals to HPH network (1). One of the interesting results in this study was that most interventions were in the domain of promoting a healthy workplace and management policy, which may be due to the fact that Ministry of Health policy is treatment-oriented and patient-oriented. The second intervention examined in this study used different health education models for intervention in various dimensions of the hospital. Any change requires education. Changing infrastructure without education and changing the awareness and attitudes of people certainly are bound to lead to a problem with the change problem. Education without proper planning and determining proper framework will not be effective. The results of this study showed that the use of appropriate health education models for each of the dimensions of the hospital can increase the efficiency of educational interventions. Using educational model of health belief in patients increased their knowledge and attitude towards the perceived barriers and benefits of health-promoting lifestyle behaviors. In his study, Shidfar referred to due application of health belief model in understanding the factors that affect lifestyle of people with heart disease and emphasized the necessity of health education programs in improving the health of patients in addition to medical services (30). Making chronic patients aware of the disease status and factors affecting it can increase the ability of the patient to control the circumstances. It also leads to increased patient satisfaction as a final outcome (31). Another appropriate educational model used in this study was a comprehensive quality management. In 1992, a group of leaders of various industries and scientific institutions members provided a definition of a comprehensive quality management in which comprehensive quality management was defined as employees-based management system whose goal was ongoing increase in the satisfaction of customers with less cost. Comprehensive quality management is an integral part of an organization strategy, not as a part of an organization. Comprehensive quality management plays a role in various organizational departments. Comprehensive quality management is implemented with the participation of all employees, from top to bottom, and it includes a chain of internal and external customers of organization (32, 33). Therefore, to increase the standard of management policy, a comprehensive quality management that promotes health should be implemented in various departments of the hospital. In general, implementing the interventions establishing health promoting standards and educational interventions based on educational models of health and management can increase the health level in hospitals and achieve HPH standards.

\section{Conclusion}

The results of this study showed that despite the large number of hospitals operating in Iran (570 public hospitals and 337 private hospitals), the number of studies conducted on HPH is small and further studies are needed. The findings of a few studies on HPH indicated that the most important challenge in achieving HPH standards is Iran's hospital policy, which is more treatment-oriented. Thus, to achieve higher HPH standards, the treatment-oriented policy of hospitals should be changed to a health promoting policy. Furthermore, to meet HPH standards, appropriate organizational and educational interventions are needed.

\section{Acknowledgments}

This review article was derived from a $\mathrm{PhD}$ dissertation 
(number: 9509235545) in Hamadan University of Medical Sciences in 2016-2017. The authors express their gratitude to Hamadan University of Medical Sciences for supporting this study. The authors declare that there is no conflict of interests.

\section{Conflict of Interests}

The authors declare that they have no competing interests.

\section{References}

1. Naderi Shima AM, Khosravi Ahmad, Riahi Leila. Effect of Health Promoting Hospitals Standards on Hospital Performance. A case Study in Fatemieh Hoapital in shahrod. Hospital. 2015;14(2).

2. Groene O. Implementing health promotion in hospitals: Manual and self-assessment forms. Implementing health promotion in hospitals: manual and self-assessment forms. 2006. p. 76.

3. Organization WH. Health promotion glossary. Geneva: World Health Organization; 1998. WHO/HPR/HEP/98.1). http://www. who. int/hpr/NPH/docs/hp glossary en. pdf (accessed 10 July 2009); 2013.

4. Delobelle P, Onya H, Langa C, Mashamba J, Depoorter AM. Advances in health promotion in Africa: promoting health through hospitals. Glob Health Promot. 2010;17:33-6.

5. Jackson SF, Perkins F, Khandor E, Cordwell L, Hamann S, Buasai S. Integrated health promotion strategies: a contribution to tackling current and future health challenges. Health Promot Int. 2006;21:7583.

6. Organization WH. The International Network of Health Promoting Hospitals and Health Services: integrating health promotion into hospitals and health services: concept, framework and organization. 2007.

7. Organization WH. The Ottawa Charter for Health Promotion World Health Organization. Geneva. 1986.

8. Groene O, Garcia-Barbero M. Health promotion in hospitals: evidence and quality management: WHO Regional Office for Europe Copenhagen; 2005

9. Pelikan JM, Krajic K, Dietscher C. The health promoting hospital $(\mathrm{HPH})$ : concept and development. Patient education and counseling. 2001;45(4):239-43

10. Heydarnia M, Abachzadeh K, Damari B, Azargashb E, Vosoughmoghaddam A. Study of expert opinion on health promotive services for patients at hospitals affiliated to Shahid Beheshti University of Medical Science. Pajoohandeh Journal. 2009;14(4):183-90.

11. Mosadeghrad A. The Handbook of Hospital Professional Organization and Management (2). Dibagran Tehran, Tehran. 2004.

12. Khamse A, Aghamohamadi S, Kazemi E. Assessing the main factors affecting waiting times referred to specialized clinics on one of the public hospitals of Tehran. 2013.

13. Yaghoubi M, Javadi M. Health promoting Hospitals in Iran: How it is. J Educ Health Promot. 2013;2(1):41.

14. Afshari A, Mostafavi F, Keshvari M,Ahmadi-Ghahnaviye L, Piruzi M, Moazam E, et al. Health promoting hospitals: a study on educational hospitals of Isfahan, Iran. Health Promot Perspect. 2016;6(1):23.

15. Yaghoubi M, Javadi M, Bahadori MK. Designing a Health Promoting Hospital: Case Study Isfahan University of Medical Sciences. Health Information Management. 2014;10(7).

16. Yaghoubi $M$, Javadi $M$, Bahadori $M$, Ravangard R. Health promoting hospitals model in Iran. Iran $\mathrm{J}$ Public Health. 2016;45(3):362.

17. Yaghoubi M, Maleki MR, Javadi M. Designing a Conceptual Model of Influencing Factors for Health Promoting Hospitals: A Comparative Study. Journal of Management And Medical Informatics School. 2014;1(2).

18. Yaghoubi M, Javadi M, Bahadori MK. Factor Analysis of Effective Factor of Health Promoting Hospital in Selected Hospital of Isfahan. Health Services Research Journal. 2013;9(8).

19. Amiri M, Khosravi A, Riyahi L, Naderi S. The Impact of Setting the Standards of Health Promoting Hospitals on Hospital Indicators in Iran. PLoS ONE. 2016;11(12):e0167459.

20. Zarei F, Taghdisi MH, Keshavarz Mohamadi N, Tehrani H. Health
Promoting Hospital: A pilot study in Bo-Ali hospital, Qazvin, Iran Journal of Fasa University of Medical Sciences. 2013;3(3):215-23.

21. Keshavarz Mohammadi N, Zarei F, Rezaei M, Keshavarz A, Kalhor R. Exploring perspectives of medical staff on hospital's effects on their health: a health promoting hospital's approach. Razi Journal of Medical Sciences. 2013;20(113):36-47.

22. Moghadam SMK. Design, implementation and evaluation of health promoting hospital program in selected hospital of Hamadan University of Medical Sciences : Developing an interventional model: Hamadan University of Medical Sciences; 2017.

23. News M. The number of Iran hospitals 2017 [Available from: http://www.mashreghnews.ir/news.

24. Michel F. The Birth of the Clinic: An archaeology of medical perception. London: Tavistock Publications. 1973.

25. Badura B. Qualitätsforschung im Gesundheitswesen: Ein Vergleich ambulanter und stationärer kardiologischer Rehabilitation: JuventaVerlag; 1995.

26. Lee CB, Chen MS, Chu CMY. The health promoting hospital movement in Taiwan: recent development and gaps in workplace. Int J Public Health. 2013;58(2):313-7.

27. Najafi, L, Hamidi, Y, Ghiasi, M, Shahhoseini, R, Emami, H. Performance evaluation and its effects on employees' job motivation in Hamedan City health centers. Aust J Basic \& Appl Sci. 2011; 5(12): 1761-1765.

28. Boskabadi H, Parvini Z, Barati T, Moudi A. Study of The Causes And Predisposing Factors In Neonatal Mortality In Ghaem Hospital (March 2009 To May 2010). 2012.

29. Amani F, Barak M, Aminisani N, Dehghan MH. Neonatal mortality and its related factors in Hospitals of Ardabil, 2002-2003. Journal of Ardabil University of Medical Sciences. 2005;5(4):305-10.

30. Shidfar M, Hosseini M, Zadeh DS, Asasi N, Majlesi F, Nazemi S. Effectiveness of an educational program on knowledge and attitudes of angina patients in Mashhad, Iran :Results of an intervention. Journal of Birjand University of Medical Sciences. 2007;14(1):9-15.

31. Meyer C, Muhlfeld A, Drexhage C, Floege J, Goepel E, Schauerte $\mathrm{P}$, et al. Clinical research for patient empowerment-A pilot study on the improvement of heart health promotion in chronic illness. Medical Science Monitor. 2008;14(7).

32. Jiang R, Fu S, Li B. The application of total quality management (TQM) in quality management of radiation therapy. Zhongguo yi liao qi xie za $\mathrm{zhi}=$ Chinese journal of medical instrumentation. 2009;33(2):131-3.

33. Hamidi,Y. Strategic leadership for effectiveness of quality managers in medical sciences universities: What skills is necessary. Aust J Basic \& Appl Sci. 2009; 3(3):2563-2569. 